\title{
Tetramethylpyrazine (TMPZ) triggers S-phase arrest and mitochondria- dependent apoptosis in lung cancer cells
}

\author{
H. H. HUANG*, F. B. LIU*, Z. RUAN, J. ZHENG, Y. J. SU, J. WANG* \\ Department of Thoracic Surgery, The First People's Hospital Affiliated to Shanghai Jiao Tong University, Shanghai, P.R. China \\ ${ }^{*}$ Correspondence: wangjin_no1@163.com \\ "Contributed equally to the work.
}

Received May 21, 2017 / Accepted July 22, 2017

\begin{abstract}
Tetramethylpyrazine (TMPZ) is one of the active compounds extracted from the traditional Chinese herb Chuanxiong. Several studies have shown its anti-cancer properties. However, its functions in lung cancer and the underlying cellular mechanisms are relatively unknown. Our present study aimed to investigate the effects of TMPZ on A549 and 95D cells. The MTT assay showed that TMPZ decreased cell viability in a dose- and time-dependent manner. The results of the colony formation assay indicated that TMPZ strongly suppressed colony formation ability in A549 and 95D cells. Flow cytometric analysis revealed that TMPZ induced S phase arrest in lung cancer cells. In addition, TMPZ induced apoptosis, as shown by the results of propidium iodide/Annexin V double-staining. Furthermore, TMPZ decreased mitochondrial membrane potential $(\triangle \Psi \mathrm{m})$ in a dose-dependent manner. Finally, western blot analysis of TMPZ-treated cells revealed the activation of Caspase- 3 and the increase of the ratio of $\mathrm{Bax} / \mathrm{Bcl}-2$. These results demonstrate that TMPZ can suppress carcinogenesis of lung cancer cells through blocking the cell cycle and inducing mitochondria-dependent apoptosis by regulating Caspase-3 and Bax/Bcl-2, suggesting that TMPZ may be a promising drug to treat lung cancer.
\end{abstract}

Key words: tetramethylpyrazine, apoptosis, cell cycle, lung cancer, mitochondrial membrane potential

Lung cancer is one of the top ten leading causes of death worldwide, accounting for $\sim 13 \%$. In recent years, traditional cancer treatments, such as surgery, chemotherapy and radiotherapy, have been widely applied for lung cancer treatment [1]. However, due to high rate of invasion and metastasis of lung cancer cells, $\sim 15 \%$ of patients survive five years after the diagnosis in the United States [2]. In China, lung cancer is the most commonly diagnosed cancer and the leading cause of cancer death in men aged 75 years or older and in women aged 60 years or older [3]. With the development of biomedical research, scientists pay more attention to traditional Chinese medicine for their anti-carcinogenic properties. Therefore, it is promising to develop new therapeutic methods for lung cancer via finding bio-active natural components in the future.

Tetramethylpyrazine (TMPZ) was one of the bioactive natural components extracted from Chinese herb Chuanxiong (Ligusticum wallichii Franch) in 1973 [4]. Chuanxiong is first described in the Chinese traditional medicine book Shennong Bencaojing as early as $200 \mathrm{BC}$ and used in many traditional clinical treatments [5]. During recent years, people have identified many pharmacological effects of TMPZ. TMPZ is applied in the treatment of neurovascular and cardiovascular diseases due to its functions of attenuation of platelet aggregation, augmentation of blood volume, inhibition of apoptosis [6], and protection against free radicals [6-8]. TMPZ has also anti-inflammatory actions in a rat asthma model [9]. Most interestingly, TMPZ has been reported to have anti-carcinogenic effects in various cancers, including breast cancer [10], ovarian cancer [11], lung cancer [12-15], hepatocellular cancer [16], glioma [17, 18], leukemia [19] and melanoma [20]. In lung cancer, TMPZ has been found to affect invasion and metastasis [13, 14]. Most recently, Zheng et al. revealed cyclooxygenase (COX)-2, a crucial enzyme in carcinogenesis, to be a molecular target of TMPZ [12]. In vitro treatment of A549 cells with TMPZ resulted in a significant inhibition of invasion, associated with reduced activities of COX-2 and MMP-2/TIMP-2 [12]. However, whether TMPZ treatment induces apoptosis of lung cancer and the underlying mechanisms are largely unknown.

In the present study, we investigated the effects of TMPZ on A549 and 95D lung cancer cell lines. In particular, we examined cell proliferation, cell cycle and apoptosis of both lung cancer cell lines and several apoptosis related proteins which are stimulated during apoptosis. 


\section{Materials and methods}

Cell lines and culture conditions. A549 cells which are adenocarcinomic human alveolar basal epithelial cells and 95D cells which are isolated from a human lung giant cell carcinoma cell line (PLA-801), a subtype of NSCLC (Non-Small Cell lung Carcinoma) which originates from epithelial cells of the lung were obtained from Cell Bank of Chinese Academy of Sciences (Shanghai, China). Both of the cell lines were maintained in Dulbecco's modified Eagle's medium (DMEM, Gibco, Grand Island, NY, USA) plus 10\% fetal bovine serum (FBS, Gibco, Grand Island, NY, USA) and $100 \mathrm{U} / \mathrm{ml}$ penicillin-streptomycin (Gibco, Grand Island, NY, USA) at $37^{\circ} \mathrm{C}$ in a humidified atmosphere of $5 \% \mathrm{CO}_{2}$.

Cell proliferation assay. TMPZ was purchased from Sigma-Aldrich Co. (St Louis, MO, USA) [21]. The effects of TMPZ on the proliferation of A549 and 95D cells were determined using the 3-(4,5-Dimethylthiazol-2-yl)-2,5-diphenyltetrazolium bromide (MTT) assay. In brief, the cells were subcultured in 96-well plates at a density of 5000 cells/well. After incubation for $24 \mathrm{~h}$, the cells were treated with 0,20 , 40, 80 and $160 \mu \mathrm{mol} / \mathrm{L} \mathrm{TMPZ} \mathrm{for} 24,48$ and $72 \mathrm{~h}$. Then $20 \mu \mathrm{l}$ MTT solution ( $5 \mathrm{mg} / \mathrm{ml}$ ) was added, followed by incubation at $37^{\circ} \mathrm{C}$ for additional $4 \mathrm{~h}$. After the medium was removed, $100 \mu \mathrm{l}$ acidic isopropanol (10\% SDS, 5\% isopropanol and $0.01 \mathrm{~mol} / \mathrm{L} \mathrm{HCl}$ ) was added into each well. The optical density of each well was measured at a wavelength of $590 \mathrm{~nm}$. All assays were performed in triplicate.

Colony formation assay. Briefly, A549 and 95D cells were subcultured in 6 well plates at a density of 400 cells/well. After adherence, cells were then cultured in media with 0,2 , 4 and $8 \mu \mathrm{mol} / \mathrm{L}$ TMPZ for 48 hours in a humidified incubator containing $5 \% \mathrm{CO}_{2}$ at $37^{\circ} \mathrm{C}$. After incubation for 2 weeks, the cells were fixed with $4 \%$ PFA and stained with $0.1 \%$ crystal violet and dried. All assays were performed in triplicate.

Cell cycle assay. For cell cycle analysis, A549 and 95D cells were subcloned in $6 \mathrm{~cm}$ dishes. After incubation at $37^{\circ} \mathrm{C}$ for $24 \mathrm{~h}$, the cells were treated with $0,20,40$ and $80 \mu \mathrm{mol} / \mathrm{L}$ TMPZ for $48 \mathrm{~h}$. The cells were then collected, washed in cold PBS and fixed with pre-cold $75 \%$ ethanol. After digestion using RNase, the cells were stained with propidium iodide (PI, $1 \mathrm{mg} / \mathrm{ml}$, Sigma-Aldrich, St Louis, MO, USA). Cell cycle distribution was then analyzed by flow cytometry (BD Biosciences, San Diego, CA, USA).

Apoptosis assay. Apoptosis of A549 and 95D cells was measured by Annexin V-FITC and PI staining followed by flow cytometry. The cells were cultured in medium containing different concentrations of TMPZ (0, 20, 40 and $80 \mu \mathrm{mol} / \mathrm{L}$ ) for $48 \mathrm{~h}$. The cells were then harvested and washed with ice-cold PBS three times. After staining with $5 \mu \mathrm{l}$ Annexin V-FITC for $15 \mathrm{~min}$ in the dark, the cells were collected and resuspended in PBS with PI $(100 \mu \mathrm{g} / \mathrm{ml})$. The cells were analyzed for apoptosis using flow cytometry.

Mitochondrial membrane potential $(\Delta \Psi \mathrm{m})$ assay. Rhodamine 123 (Rh123) is a cell membrane permeable, fluorescent dye which is a lipophilic cation accumulated by mitochondria in proportion to $\Delta \Psi \mathrm{m}$. Upon accumulation, Rhodamine 123 exhibits a red shift in both its absorption and fluorescence emission spectra. The fluorescence intensity is quenched when the dye is accumulated by mitochondria. $\Delta \Psi \mathrm{m}$ was measured by flow cytometry with Rh123-FITC staining. A549 and 95D cells were subcultured in a 6-well plate. After adherence, the cells were cultured in medium containing different concentrations of TMPZ (0, 20, 40 and $80 \mu \mathrm{mol} / \mathrm{L}$ ) for $48 \mathrm{~h}$. Cells were then washed twice with PBS and stained with Rh123. After incubation at $37^{\circ} \mathrm{C}$ for $30 \mathrm{~min}$ in the dark, the cells were collected and resuspended in PBS and were analyzed immediately by flow cytometry.

Western blotting. A549 and 95D cells were subcultured in a 6-well plate. After adherence, the cells were cultured in medium containing different concentrations of TMPZ (0, 20, 40 and $80 \mu \mathrm{mol} / \mathrm{L})$ for $48 \mathrm{~h}$. Cells were then washed with ice-cold PBS and lysed in $2 \times$ SDS sample buffer (100 mM Tris- $\mathrm{HCl}$ (pH6.8), $10 \mathrm{mM}$ EDTA, 4\% SDS, $10 \%$ glycine). Equal amount of protein samples was run on the $10 \%$ SDS-PAGE gel at $50 \mathrm{~V}$ for $3 \mathrm{~h}$. The proteins were then transferred to polyvinylidene fluoride (PVDF) membrane at $300 \mathrm{~mA}$ for $1.5 \mathrm{~h}$. The membrane was blocked by $1 \%$ bovine serum albumin (BSA) in TBST at RT for $1 \mathrm{~h}$ and incubated with primary antibodies, anti-cleaved caspase 3 (1:1000, Cell Signaling Technology, Danvers, MA, USA), anti-Bax (1:1000, Cell Signaling Technology, Danvers, MA, USA), anti-Bcl-2 (1:1000, Cell Signaling Technology, Danvers, MA, USA), anti-p53 (1:1500, Santa Cruz Biotechnology, CA, USA), anti-cytochrome c (1:1000, Cell Signaling Technology, Danvers, MA, USA) and anti- $\beta$-actin (1:1000, Cell Signaling Technology, Danvers, MA, USA) overnight at $4^{\circ} \mathrm{C}$. After washing with TBST, membranes were incubated with horseradish peroxidase-conjugated goat anti-mouse (1:5000, Abcam, Cambridge, UK) and goat anti-rabbit (1:5000, Abcam, Cambridge, UK) secondary antibodies for $2 \mathrm{~h}$ at room temperature. The membrane was washed with TBST and signals were detected by enhanced chemiluminescence (Pierce, Rockford, IL, USA).

In vivo xenograft study. Six-weeks old nude mice $(\sim 18 \mathrm{~g}$ body weight) were purchased from Shanghai SLAC Laboratory Animal Co., Ltd. (Shanghai, People's Republic of China). All animal treatments were approved by the Institutional Animal Care and Use Committee of Shanghai Jiao Tong University. A549 cells in log-phase growth were resuspended in serum-free culture medium (at a density of $1 \times 10^{6}$ cells in $0.2 \mathrm{~mL}$ ). Tumor xenografts were established by subcutaneous inoculation of A549 cells into the right flank of nude mice. Twenty-four hours later, the mice were randomly divided into 4 groups (10 mice/group). One group was administrated with vehicle (10\% DMSO and 90\% PBS) intraperitoneally (IP) and the others were administrated with TMPZ (40, 80 and $160 \mathrm{mg} / \mathrm{kg}$ ) IP in a volume of $0.2 \mathrm{ml}$ every 2 days for up to 20 days. Tumor volume was measured and estimated with the following formula: tumor volume $\left(\mathrm{mm}^{3}\right)=(\mathrm{L} \times \mathrm{W} 2) / 2$ 
( $\mathrm{L}$ represents the length and $\mathrm{W}$ represents the width of tumors). On day 21, the tumors were removed from the mice and weighed.

Statistical analysis. Comparisons between groups were done using paired Student's $t$ test, and differences were considered statistically significant at $\mathrm{p}<0.05$. Data are presented as mean \pm standard deviation (SD).

\section{Results}

TMPZ inhibits cell growth and colony formation abilities of A549 and 95D cells. To investigate the potential functions of TMPZ in lung cancer cells, we treated A549 and 95D cells using different concentrations of TMPZ (0,20, 40, 80 and $160 \mu \mathrm{mol} / \mathrm{L})$ for 24,48 and $72 \mathrm{~h}$, respectively. MTT

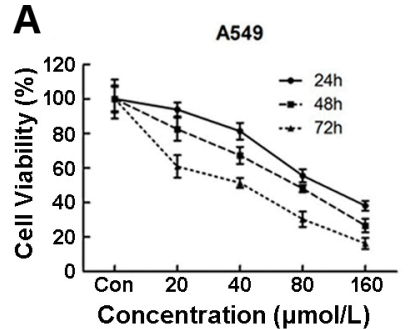

C

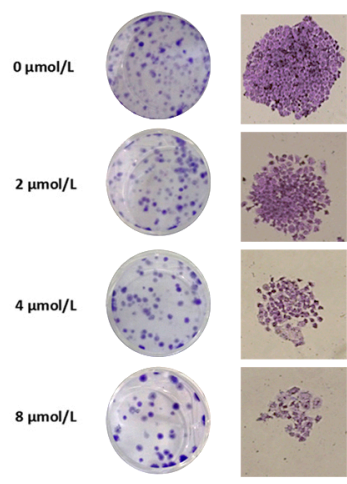

$\mathbf{E}$

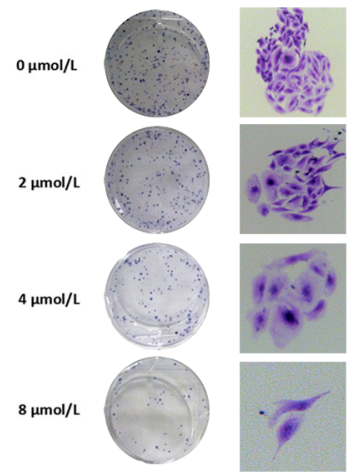

B

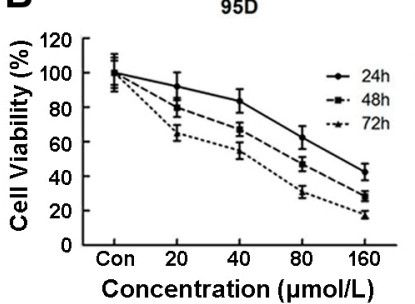

D

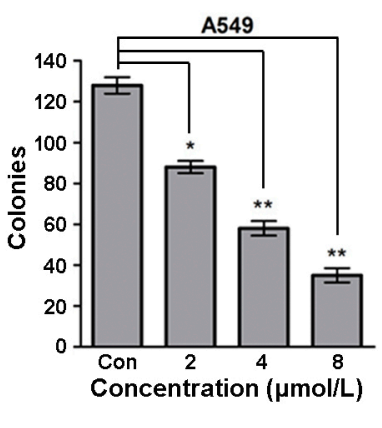

$\mathbf{F}$

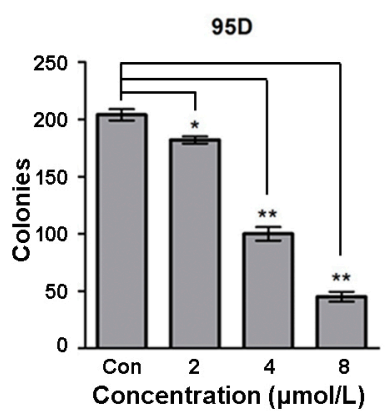

G

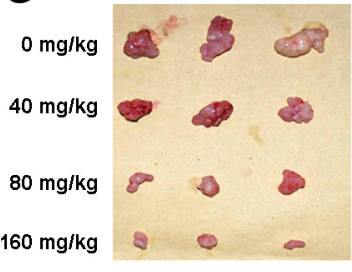

H

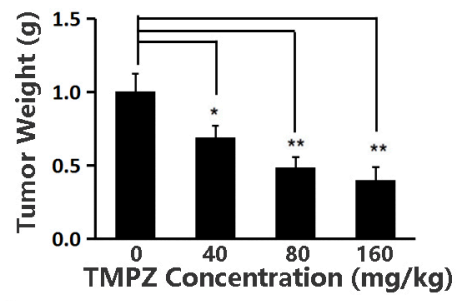

I

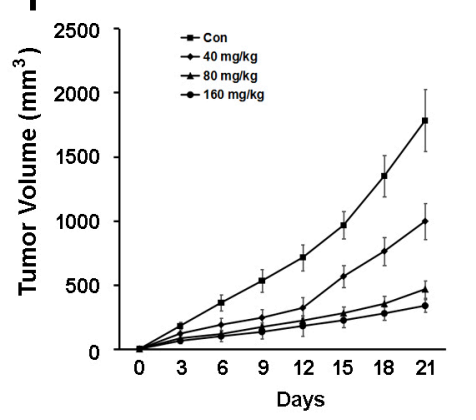

J

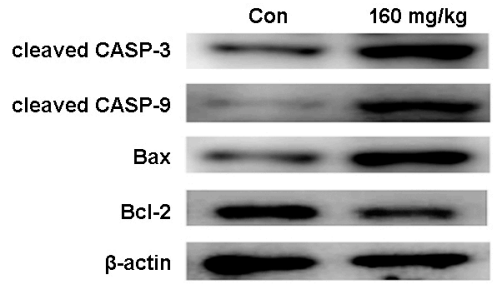

Figure 1. TMPZ inhibits cell growth and colony formation abilities of A549 and 95D cells. (A-B) MTT assays of cell viability of A549 (A) and 95 D cells $(B)$ at 24,48 and $72 \mathrm{~h}$ after treatment with TMPZ $(0,20,40,80$ and $160 \mu \mathrm{mol} / \mathrm{L})$. (C, E) Representative images of crystals violet staining assays of TMPZ (0, 2, 4 and $8 \mu \mathrm{mol} / \mathrm{L}$ ) treated A549 (C) and 95D cells (E). (D, F) Colony numbers of TMPZ treated A549 (D) and 95D cells (F). (G) Photos of representative tumors from each group are presented to show sizes of the tumors from different groups. $(\mathrm{H})$ Tumors of different groups were weighed. The data are expressed as the mean \pm SD $(n=10)$. (I) Tumor dimensions were periodically measured. $(\mathrm{J})$ The expression levels of apoptosis-related proteins in tumor tissues were assessed by western blot analysis. $\beta$-actin was used as the internal control. ${ }^{*}, p<0.05,{ }^{* *}, p<0.01$. Each experiment was repeated at least three times. 

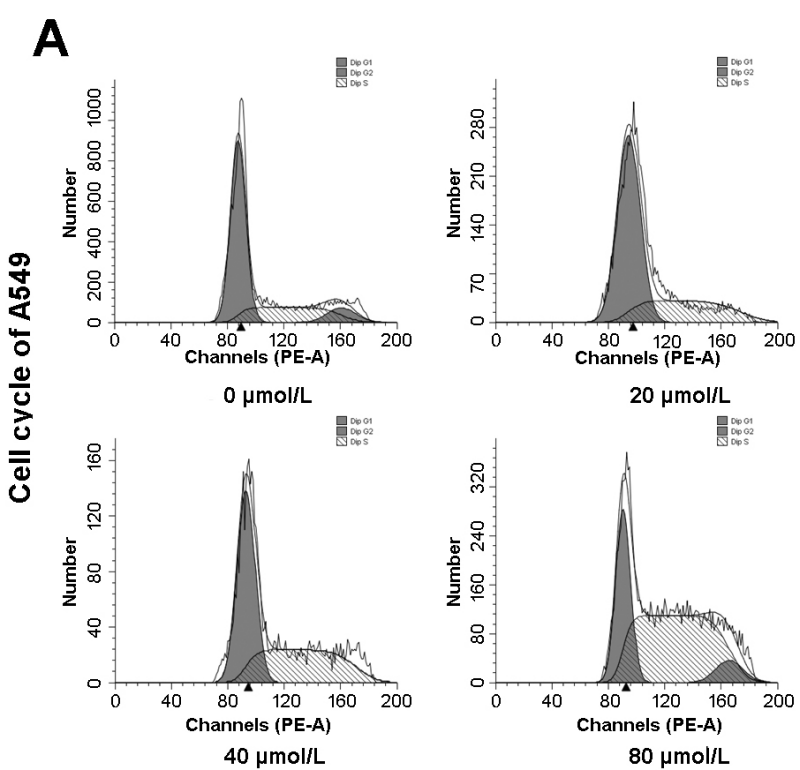

$80 \mu \mathrm{mol} / \mathrm{L}$
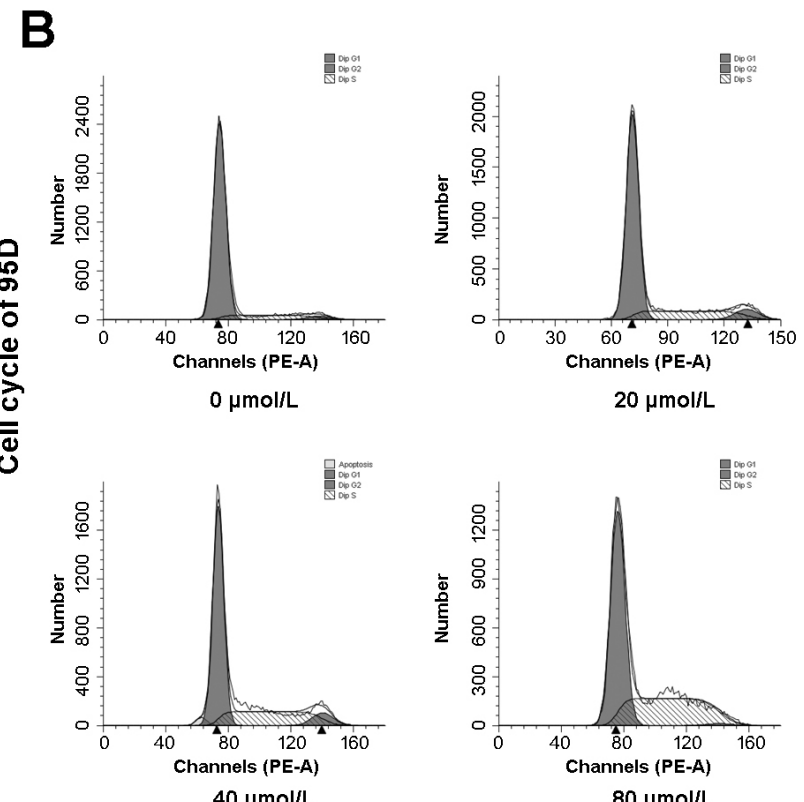

$80 \mu \mathrm{mol} / \mathrm{L}$

C
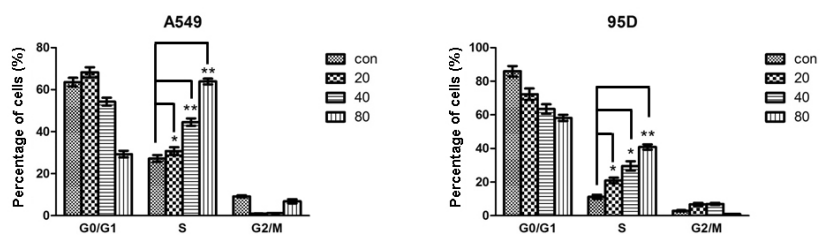

Figure 2. TMPZ blocks cell cycle progressions of A549 and 95D cells. (A, B) Representative graphs of flow cytometry analysis of cell cycle stages of TMPZ $(0,20,40$ and $80 \mu \mathrm{mol} / \mathrm{L})$ treated A549 (A) and $95 \mathrm{D}$ cells (B). (C) Statistic analysis of cells numbers in $G_{0} / G_{1}, S$ and $G_{2} / M$ stages of TMPZ treated A549 (Left) and 95 D cells (Right). ${ }^{*}, \mathrm{p}<0.05,{ }^{* *}, \mathrm{p}<0.01$. Each experiment was repeated at least three times. assays showed that cell viability was significantly reduced along with increased TMPZ concentrations in both cell lines (Figure 1A-B). There were only $\sim 20 \%$ alive cells detected $72 \mathrm{~h}$ after treatment with $160 \mu \mathrm{mol} / \mathrm{L}$ TMPZ. These results indicate that TMPZ could significantly inhibit lung cancer cell growth. In the proliferation assay, the viability of cells was significantly suppressed with TMPZ incubation for $24 \mathrm{~h}, 48 \mathrm{~h}$ and $72 \mathrm{~h}$. Only the cells incubated for $48 \mathrm{~h}$ showed a moderate inhibition. Thus, $48 \mathrm{~h}$ time point was chosen for other assays in our study. Then, we analyzed the colony formation of A549 and 95D cells treated by 0,2, 4 and $8 \mu \mathrm{mol} / \mathrm{L} \mathrm{TMPZ}$. The colony numbers of both cell lines were decreased in a concentration dependent manner, especially at $8 \mu \mathrm{mol} / \mathrm{L} \mathrm{TMPZ} \mathrm{(only} \sim 1 / 4$ of control cells with no TMPZ treatment) (Figure $1 \mathrm{C}-\mathrm{F}$ ). The cell numbers in each colony were also reduced accordingly (Figure 1C, 1E).

To determine the anti-tumor effect of TMPZ in vivo, we measured the tumor volume and tumor weight in a xenograft animal model in which mice were injected with A549 cells and were administrated TMPZ or vehicle (10\% DMSO and $90 \%$ PBS) every 2 days for up to 20 days. Figure 1G shows the tumors from the experimental animals. The results show that the mean weights and volumes were remarkably reduced in mice treated with TMPZ compared with the control mice treated with vehicle in a dose dependent manner (Figure $1 \mathrm{H}$, 1I). Both in vitro and in vivo data suggest that the cell proliferation ability is impaired severely by TMPZ treatment.

TMPZ blocks cell cycle progressions of A549 and 95D cells. To find out the underlying mechanisms, we performed flow cytometry to analyze the cell cycle of $\operatorname{TMPZ}(0,20,40$ and $80 \mu \mathrm{mol} / \mathrm{L}$ ) treated lung cancer cells using PI staining. As shown in Figure 2, the cell numbers at $G_{0} / G_{1}$ phase were reduced in both A549 and 95D cells, while there were more cells detected in S phase. PI staining assay results showed significant increase in the percentage of cells in the $S$ phase $(29.24 \pm 5.14 \%$ for $20 \mu \mathrm{mol} / \mathrm{L}$ TMPZ, $42.28 \pm 5.67 \%$ for $40 \mu \mathrm{mol} / \mathrm{L} \mathrm{TMPZ}$ and $62.28 \pm 5.38 \%$ for $80 \mu \mathrm{mol} / \mathrm{L}$ TMPZ vs. $24.68 \pm 4.33 \%$ in the control group in A549 cells; $20.9 \pm 5.44 \%$ for $20 \mu \mathrm{mol} / \mathrm{L}$ TMPZ, $27.19 \pm 5.68 \%$ for $40 \mu \mathrm{mol} / \mathrm{L} \mathrm{TMPZ}$ and $40.96 \pm 4.99 \%$ for $80 \mu \mathrm{mol} / \mathrm{L}$ TMPZ vs. $11.57 \pm 2.18 \%$ in the control group in $95 \mathrm{D}$ cells). These results indicate that cell cycle of lung cancer cells is stuck in S phase after treatment with TMPZ, which leads to cell proliferation inhibition (Figure 2).

TMPZ induced apoptosis of A549 and 95D cells. To test whether apoptosis is induced by TMPZ treatment in lung cancer cells, we analyzed TMPZ $(0,20,40$ and $80 \mu \mathrm{mol} / \mathrm{L})$ treated A549 and 95D cells using PI and Annexin V double staining and flow cytometry. In normal living cells, phosphatidyl serine (PS) is located on the cytoplasmic surface of the cell membrane. However, in apoptotic cells, PS is translocated from the inner to the outer leaflet of the plasma membrane, exposing PS to the external environment. In that case, Annexin V binds to exposed PS on apoptotic and necrotic cells while PI enters into late apoptotic cells and necrotic 
A

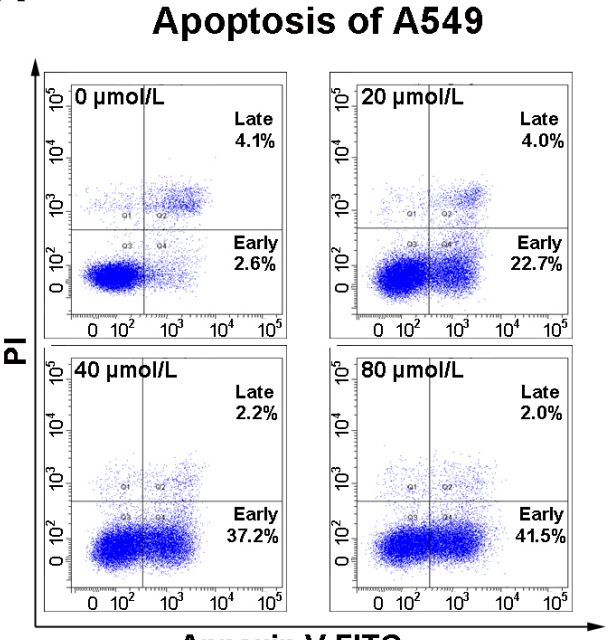

Annexin V-FITC

\section{C}

Apoptosis of 95D

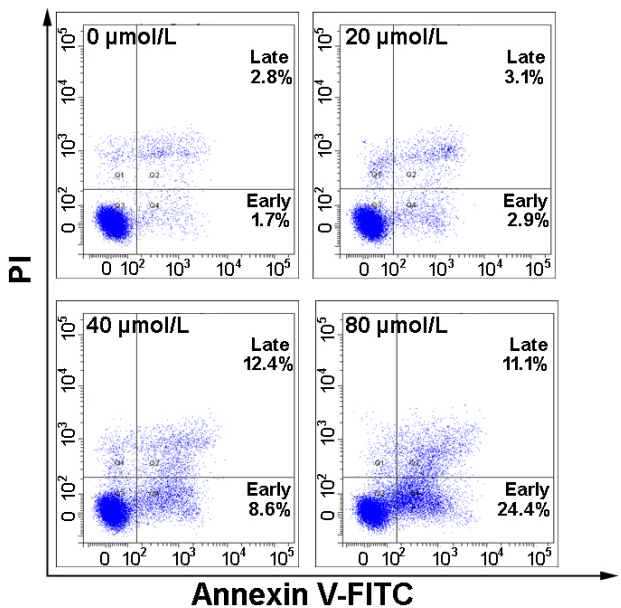

B

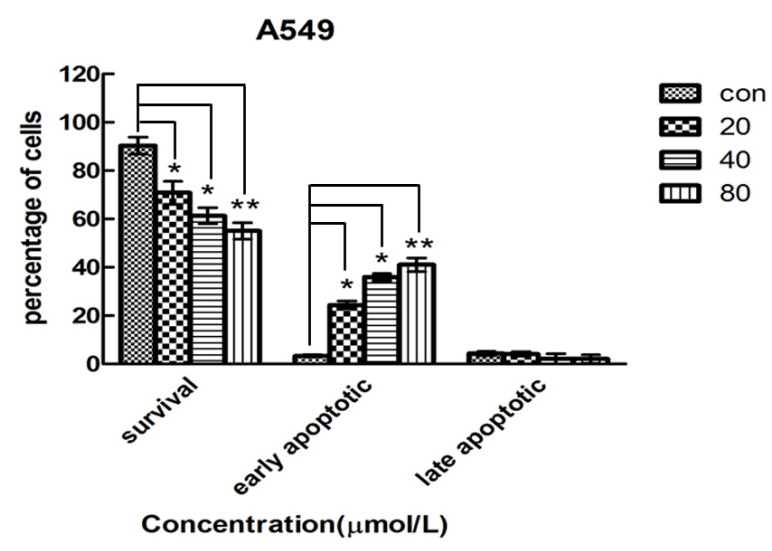

D

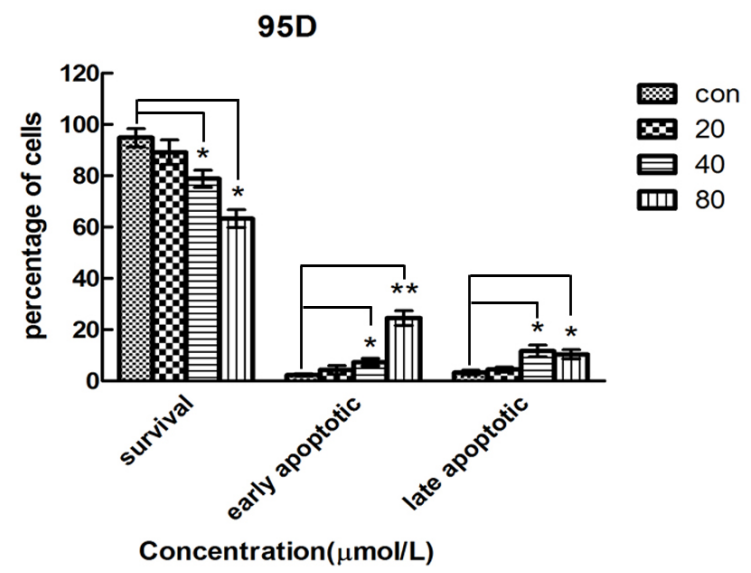

Figure 3. TMPZ induced apoptosis of A549 and 95D cells. (A, C) Representative graphs of flow cytometry analysis of apoptosis of TMPZ (0, 20, 40 and $80 \mu \mathrm{mol} / \mathrm{L}$ ) treated A549 (A) and $95 \mathrm{D}$ cells (C). "Late" represents late apoptosis and "Early" represents early apoptosis. The percentage of cells in early or late apoptotic state is indicated in figure. (B, D) Statistic analysis of cells numbers at different populations of TMPZ treated A549 (B) and 95 D cells (D). $\mathrm{PI}^{-} /$Annexin $\mathrm{V}^{-}$, survival cells; $\mathrm{PI}^{-} / A n n e x i n \mathrm{~V}^{+}$, early apoptotic cells; $\mathrm{PI}^{+} /$Annexin $\mathrm{V}^{+}$, late apoptotic cells. ${ }^{*}, \mathrm{p}<0.05$, ${ }^{\star *}, \mathrm{p}<0.01$. Each experiment was repeated at least three times.

cells but not into early apoptotic cells and living cells. With increased concentrations of TMPZ, fewer surviving cells $\left(\mathrm{PI}^{-} /\right.$Annexin $\left.\mathrm{V}^{-}\right)$, while more apoptotic cells $\left(\right.$Annexin $\left.\mathrm{V}^{+}\right)$ were detected (Figure 3). As shown in Figure 3, TMPZ reduced the number of surviving cells and increased the number of early apoptotic cells in a dose-dependent manner $(22.7 \pm 3.57 \%$ for $20 \mu \mathrm{mol} / \mathrm{L} \mathrm{TMPZ}, 37.2 \pm 3.43 \%$ for $40 \mu \mathrm{mol} / \mathrm{L}$ TMPZ and $41.5 \pm 2.79 \%$ for $80 \mu \mathrm{mol} / \mathrm{L}$ TMPZ vs. $2.6 \pm 0.42 \%$ in the control group in A549 cells; $2.9 \pm 0.88 \%$ for $20 \mu \mathrm{mol} / \mathrm{L}$ TMPZ, $8.6 \pm 1.82 \%$ for $40 \mu \mathrm{mol} / \mathrm{L}$ TMPZ and $24.4 \pm 1.41 \%$ for $80 \mu \mathrm{mol} / \mathrm{L}$ TMPZ vs. $1.7 \pm 0.42 \%$ in the control group in 95D cells). In particular, most of the apoptosis in A549 and $95 \mathrm{D}$ cells occurred at early stage $\left(\mathrm{PI}^{-} /\right.$Annexin $\left.\mathrm{V}^{+}\right)(\sim 40 \%$ for $80 \mu \mathrm{mol} / \mathrm{L} \mathrm{TMPZ} \mathrm{treated} \mathrm{A549} \mathrm{cells} \mathrm{and} \sim 25 \%$ for $80 \mu \mathrm{mol} / \mathrm{L}$ TMPZ treated 95D cells). These results suggest that TMPZ induces apoptosis in lung cancer cells.

TMPZ leads to loss of $\Delta \Psi \mathrm{m}$ in A549 and 95D cells. Mitochondria play an important role in the regulation of apoptosis, and apoptosis mediated by this pathway is often associated with the decrease of $\Delta \Psi \mathrm{m}$. In order to investigate 
whether mitochondrial membrane integrity is damaged by treatment with TMPZ, we therefore used flow cytometry to determine the effect of TMPZ on mitochondrial membrane integrity using the fluorescent dye Rh123, which could stain intact mitochondria. As shown in Figure 4, most untreated A549 and 95D cells showed high Rh123 signals, while dosedependent decreases of $\triangle \Psi \mathrm{m}$ were detected in TMPZ treated cells. These results indicate that most lung cancer cells have intact mitochondria membrane and TMPZ treatment leads to loss of $\Delta \Psi \mathrm{m}$. Consistent with the results of PI/Annexin V staining (Figure 3), 40\% of A549 and 95D cells treated with $80 \mu \mathrm{mol} / \mathrm{L}$ TMPZ were Rh123 negative cells, which are supposed to be apoptotic cells (Figure 4). These results indicate that TMPZ induces mitochondria-dependent pathway of apoptosis.

TMPZ upregulates cleaved Caspase 3 and $\mathrm{Bax} / \mathrm{Bcl} 2$ expressions in A549 and 95D cells. It is well known that proteins in the caspase family and Bcl-2 family play important roles in the apoptotic process. We then analyzed the expression of apoptosis related proteins by western blotting. As shown in Figure 5, more cleaved Caspase 3 and Bax were detected while the expression of $\mathrm{Bcl}-2$ decreased remarkably in TMPZ treated A549 and 95D cells. Treatment with TMPZ also increased the levels of p53 and cytosol cytochrome $c$ in a dose-dependent manner, which may be responsible for the TMPZ-induced apoptotic tendency in A549 and 95D cells. When we explored the mechanisms by which TMPZ exerts its effects on lung cancer in a xenograft animal model, the results were in accordance with those from the in vitro experiments (Figure 1J). These results suggest that TMPZ upregulates the apoptosis related proteins, such as cleaved Caspase 3 and the ratio of $\mathrm{Bax} / \mathrm{Bcl} 2$, in lung cancer cells.

\section{Discussion}

TMPZ, as a bioactive component of Chuanxiong, has been applied in different types of cancers, and displays anticarcinogenic properties. In the present study, we mainly
A

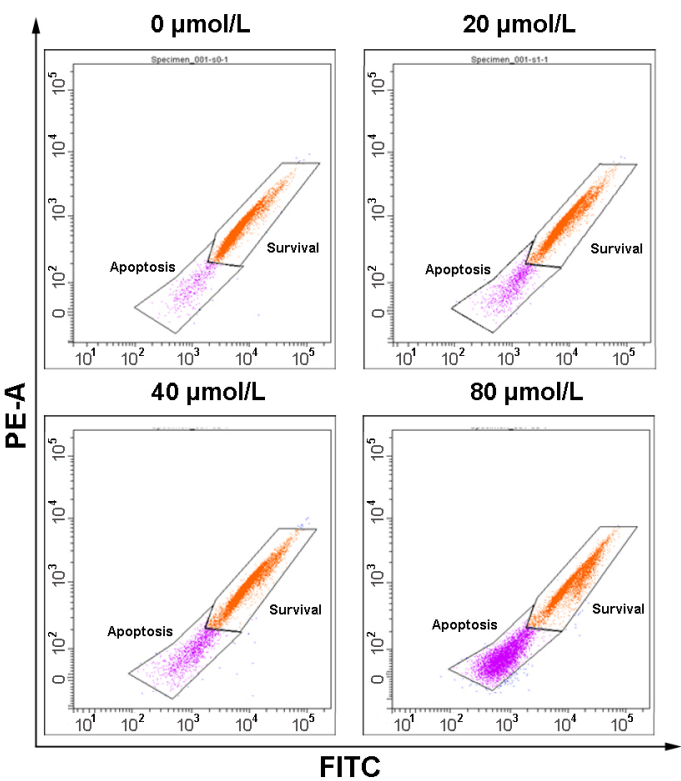

B

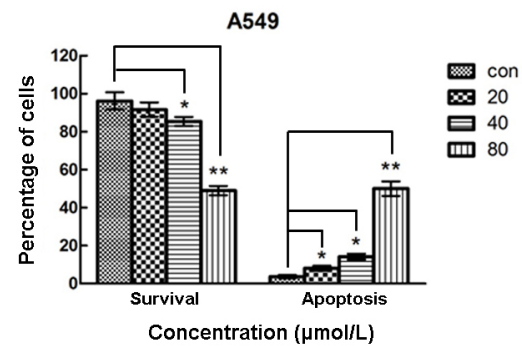

C

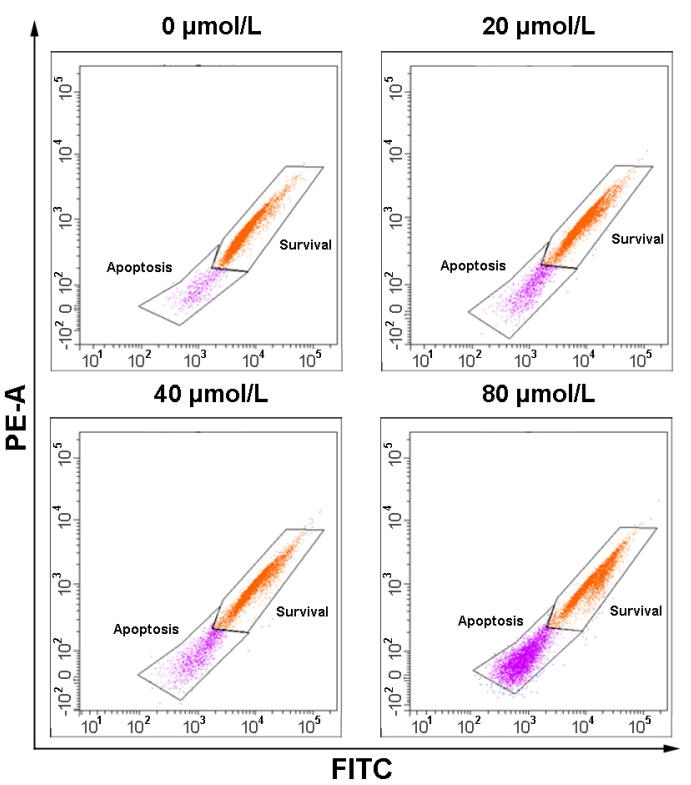

D

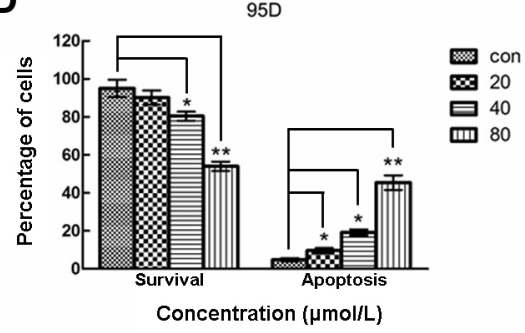

Figure 4. TMPZ leads to loss of $\Delta \Psi \mathrm{m}$ in A549 and 95D cells. (A, C) Representative graphs of flow cytometry analysis of $\Delta \Psi \mathrm{m}$ of TMPZ (0, 20, 40 and 80 $\mu \mathrm{mol} / \mathrm{L})$ treated A549 (A) and $95 \mathrm{D}$ cells (C). (B, D) Statistic analysis of cell numbers at different populations of TMPZ treated A549 (B) and $95 \mathrm{D}$ cells

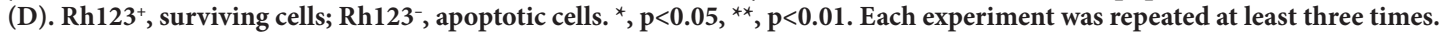


focused on apoptosis of lung cancer cells induced by TMPZ, using two lung cancer cell lines, A549 and 95D cells. TMPZ could arrest cell cycle progression and induce mitochondria dependent apoptosis through upregulation of Caspase- 3 and $\mathrm{Bax} / \mathrm{Bcl}-2$, which leads to reduced cell viability and impaired colony formation ability.

Zheng et al. [12] showed the in vitro inhibitory effect of TMPZ on lung cancer A549 cell proliferation, invasion and metastasis. The expression of COX-2 is inhibited in TMPZ treated A549 cells [12]. Previous studies showed that silencing or suppression of COX-2 leads to increased apoptosis in breast cancer, bladder cancer and gastric cancer cells [22-24]. Other studies found that induction of apoptosis by TMPZ is associated with the activation of the ROS/AMPK pathway in gastric cancer cells [25] and down-regulation of NF- $\kappa B$ in osteosarcoma cells [26]. Thus, TMPZ might regulate apoptosis through regulating COX-2 or other pathways. The detailed mechanisms of TMPZ induced apoptosis in lung cancer need further studies.

Most recently, using a A549 xenograft tumor mouse model, Jia et al. [27] found that TMPZ could suppress angiogenesis and tumor growth of lung cancer in vivo. Consistent with previous reports [12], our studies confirmed that the cell proliferation was significantly inhibited by TMPZ in a time- and dose-dependent manner (Figure 1). Cell cycle was arrested in S-phase in TMPZ treated A549 and 95D cells (Figure 2). TMPZ treatment significantly inhibits CD31, phosphorylated Smad1/5/8 and Id-1 expression in xenograft tumors. BMP/Smad signaling pathway regulates cell proliferation in tumor cells [27]. TMPZ was also found to suppress osteosarcoma cell proliferation through upregulating cytosolic NF- $\kappa \mathrm{B}$ p65 and downregulating nuclear NF- $\kappa \mathrm{B}$ p65, Bcl-2 and cylcin D1 [26]. TMPZ might affect tumor cell growth via regulating multiple pathways. The underlying mechanisms still need to be investigated in further study.

In order to detect the proliferative capacity of cells treated with different concentrations of TMPZ, the colony formation assay which is an effective method for the determination of single cell proliferation capacity was employed in this research. The basic principle of this assay is that a single cell continues to proliferate for more than six generations in vitro and becomes a clone containing more than 50 cells. We found that colony numbers and sizes of both cell lines were reduced dramatically after treatment with TMPZ, suggesting that the cell proliferative capacity was largely suppressed by TMPZ treatment.

The mitochondrial pathway of apoptosis is one of the key safeguards against carcinogenesis and a promising therapeutic target in cancer [28-30]. TMPZ treatment causes early-stage apoptosis and loss of $\Delta \Psi \mathrm{m}$ in A549 and 95D cells (Figures 3 and 4), indicating that TMPZ leads to mitochondriadependent apoptosis in lung cancer cells. In mitochondriadependent apoptosis, Bcl-2 functions as one of the antiapoptotic effectors and $\mathrm{Bax}$ as one of the pro-apoptotic effectors of cell death $[31,32]$. The up-regulation of Bcl-2

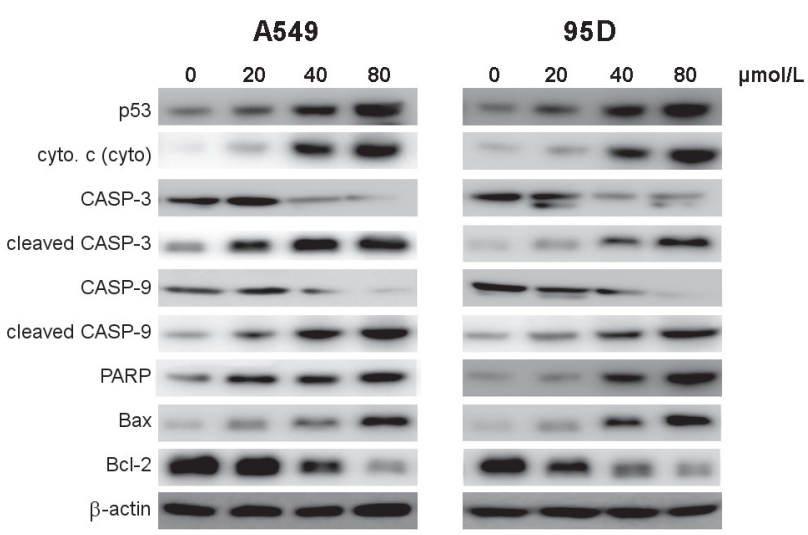

Figure 5. TMPZ upregulates cleaved Caspase 3 and $\mathrm{Bax} / \mathrm{Bcl} 2$ expressions in A549 and 95D cells. The expression of p53, cytosol cytochrome c, cleaved Caspase-3, cleaved Caspase-9, PARP, Bax and Bcl-2 were detected using western blotting in TMPZ $(0,20,40$ and $80 \mu \mathrm{mol} / \mathrm{L})$ treated A549 (Left) and $95 \mathrm{D}$ cells (Right). $\beta$-actin was used as the internal control.

is usually a common feature in cancer [28]. Bcl-2 controls the integrity of the outer membranes of mitochondria. Its interactions with Bax disrupt the mitochondria membrane through mitochondrial outer membrane permeabilization [33]. Then proteins in the mitochondrial intermembrane space enter the cytosol and cause the activation of caspases, such as Caspase-3 which is a frequently activated death protease during apoptosis [34]. In TMPZ treated A549 and 95D cells, expression of Bcl-2 was high in untreated cells and decreased significantly in a dose-dependent manner, while Bax levels increased. As predicted, the active Caspase- 3 is also upregulated after TMPZ treatment in a dose-dependent manner (Figure 5). Thus, TMPZ could regulate $\mathrm{Bax} / \mathrm{Bcl}-2$ expression to modulate Caspase- 3 activity and mitochondria-dependent apoptosis in lung cancer cells.

TMPZ is well-known for its protective effect on myocardial ischemia-reperfusion injury (MIRI) [35]. In contrast to what we found in tumor cells, studies showed that TMPZ inhibits apoptosis and protects myocardial cells and PC12 cells $[36,37]$. It has also been reported that TMPZ improved neurovascular recovery by protecting retinal astroglia cells and neurons from ischemia-induced cell death due to its downregulation of HIF-1 and VEGF expression [6]. However, TMPZ induced apoptosis via mitochondrial pathway of apoptosis in treatment of lung cancer cells in our research. These controversial conclusions from different groups may partially be due to the different cell models used in the research. However, the different functions of TMPZ in lung cancer cells and avascular retina still need to be further investigated.

In conclusion, our studies confirm that TMPZ can sufficiently suppress lung cancer cells, such as A549 and 95D cells, proliferation and colony formation. Cell cycle progression is impaired by treatment with TMPZ. We demonstrate for the first time that TPMZ could induce apoptosis in lung cancer 
cells via mitochondria-dependent pathway and stimulation of Caspase- 3 and $\mathrm{Bax} / \mathrm{Bcl}-2$. Our studies shed new light on the mechanisms underlying anti-carcinogenic functions of TMPZ and confirm that TMPZ is a promising bioactive component for lung cancer therapy.

\section{References}

[1] LIAM CK, ANDARINI S, LEE P, HO JC, CHAU NQ et al. Lung cancer staging now and in the future. Respirology 2015; 20: 526-534. https://doi.org/10.1111/resp.12489

[2] COLLINS LG, HAINES C, PERKEL R, ENCK RE. Lung cancer: diagnosis and management. Am Fam Physician 2007; 75: 56-63.

[3] CHEN W, ZHENG R, BAADE PD, ZHANG S, ZENG H et al. Cancer statistics in China, 2015. CA Cancer J Clin 2016; 66: 115-132. https://doi.org/10.3322/caac.21338

[4] BEIJING INSTITUTE OF PHARMACEUTICAL INDUSTRY. [Studies of active components of Ligusticum wallichii Franch. I. Extraction, isolation and structure identification of tetramethylpyrazine]. Chinese Med J 1977; 7: 420-421.

[5] ZHANG XL, XU JD, ZHU LY, LIU LF, LI SL et al. [Research Progress of traditional Chinese Herb Chuanxiong]. J Chin Med Mater 2012; 35: 1706-1711.

[6] LIANG X, ZHOU H, DING Y, LI J, YANG C et al. TMP prevents retinal neovascularization and imparts neuroprotection in an oxygen-induced retinopathy model. Invest Ophthalmol Vis Sci 2012; 53: 2157-2169. https://doi.org/10.1167/ iovs.11-9315

[7] KWAN CY. Plant-derived drugs acting on cellular Ca2+ mobilization in vascular smooth muscle: tetramethylpyrazine and tetrandrine. Stem Cells 1994; 12: 64-67. https://doi. org/10.1002/stem.5530120111

[8] KWAN CY, DANIEL EE, CHEN MC. Inhibition of vasoconstriction by tetramethylpyrazine: does it act by blocking the voltage-dependent Ca channel? J Cardiovasc Pharmacol 1990; 15: 157-162.

[9] FAN L, WANG K, SHI Z, DIE J, WANG C et al. Tetramethylpyrazine protects spinal cord and reduces inflammation in a rat model of spinal cord ischemia-reperfusion injury. J Vasc Surg 2011; 54: 192-200. https://doi.org/10.1016/j. jvs.2010.12.030

[10] ZHANG Y, LIU X, ZUO T, LIU Y, ZHANG JH. Tetramethylpyrazine reverses multidrug resistance in breast cancer cells through regulating the expression and function of Pglycoprotein. Med Oncol 2012; 29: 534-538. https://doi. org/10.1007/s12032-011-9950-8

[11] YIN J, YU C, YANG Z, HE JL, CHEN WJ et al. Tetramethylpyrazine inhibits migration of SKOV3 human ovarian carcinoma cells and decreases the expression of interleukin- 8 via the ERK1/2, p38 and AP-1 signaling pathways. Oncol Rep 2011; 26: 671-679. https://doi.org/10.3892/or.2011.1334

[12] ZHENG CY, XIAO W, ZHU MX, PAN XJ, YANG ZH et al. Inhibition of cyclooxygenase- 2 by tetramethylpyrazine and its effects on A549 cell invasion and metastasis. Int J Oncol 2012; 40: 2029-2037. https://doi.org/10.3892/ijo.2012.1375
[13] ZHANG P, PEI Y, QI Y. [Influence of blood-activating drugs on adhesion and invasion of cells in lung cancer patients]. Zhongguo Zhong Xi Yi Jie He Za Zhi 1999; 19: 103-105.

[14] CHEN SX, WANG LX, XING LL. [Effects of tetramethylpyrazine on platelet functions of advanced cases of lung carcinoma]. Zhongguo Zhong Xi Yi Jie He Za Zhi 1997; 17: 531-533.

[15] ZHANG HJ, YAN YL, ZHANG ZX, LI JK, LIU JF et al. [Apoptosis of human small cell lung cancer H446 cells induced by tetramethylpyrazine]. Cancer Res Prev Treat 2003; 30: 452-454.

[16] WANG XB, WANG SS, ZHANG QF, LIU M, LI HL et al. Inhibition of tetramethylpyrazine on P-gp, MRP2, MRP3 and MRP5 in multidrug resistant human hepatocellular carcinoma cells. Oncol Rep 2010; 23: 211-215.

[17] FU YS, LIN YY, CHOU SC, TSAI TH, KAO LS et al. Tetramethylpyrazine inhibits activities of glioma cells and glutamate neuro-excitotoxicity: potential therapeutic application for treatment of gliomas. Neuro Oncol 2008; 10: 139-152. https://doi.org/10.1215/15228517-2007-051

[18] YU K, CHEN Z, PAN X, YANG Y, TIAN S et al. Tetramethylpyrazine-mediated suppression of C6 gliomas involves inhibition of chemokine receptor CXCR4 expression. Oncol Rep 2012; 28: 955-960. https://doi.org/10.3892/or.2012.1866

[19] WU Y, XU Y, GU X, HU Y, WANG C. [Molecular mechanism of tetramethylpyrazine to induce human promyelocytic HL-60 leukemia cells differentiation]. Zhongguo Zhong Yao Za Zhi 2011; 36: 3007-3011.

[20] CHEN L, LU Y, WU JM, XU B, ZHANG LJ et al. Ligustrazine inhibits B16F10 melanoma metastasis and suppresses angiogenesis induced by Vascular Endothelial Growth Factor. Biochem Biophys Res Commun 2009; 386: 374-379. https://doi. org/10.1016/j.bbrc.2009.06.042

[21] XU Q, XIA P, LI X, WANG W, LIU Z et al. Tetramethylpyrazine Ameliorates High Glucose-Induced Endothelial Dysfunction by Increasing Mitochondrial Biogenesis. PLoS One 2014; 9: e88243. https://doi.org/10.1371/journal. pone. 0088243

[22] LIN F, LUO J, GAO W, WU J, SHAO Z et al. COX-2 promotes breast cancer cell radioresistance via p38/MAPK-mediated cellular anti-apoptosis and invasiveness. Tumour Biol 2013; 34: 2817-2826. https://doi.org/10.1007/s13277-013-0840-x

[23] ZUO W, WANG ZZ, XUE J. Artesunate apoptosis of bladder cancer cells by miR-16 regulation of COX-2 expression. Int J Mol Sci 2014; 15: 14298-14312. https://doi.org/10.3390/ ijms 150814298

[24] WU XL, CHENG B, LI PY, HUANG HJ, ZHAO Q et al. MicroRNA-143 suppresses gastric cancer cell growth and induces apoptosis by targeting COX-2. World J Gastroenterol 2013; 19: 7758-7765. https://doi.org/10.3748/wjg.v19. i43.7758

[25] YI B, LIU D, HE M, LI Q, LIU T et al. Role of the ROS/AMPK signaling pathway in tetramethylpyrazine-induced apoptosis in gastric cancer cells. Oncol Lett 2013; 6: 583-589. https:// doi.org/10.3892/ol.2013.1403

[26] WANG Y, FU Q, ZHAO W. Tetramethylpyrazine inhibits osteosarcoma cell proliferation via downregulation of NFkappaB in vitro and in vivo. Mol Med Rep 2013; 8: 984-988. https://doi.org/10.3892/mmr.2013.1611 
[27] JIA Y, WANG Z, ZANG A, JIAO S, CHEN S et al. Tetramethylpyrazine inhibits tumor growth of lung cancer through disrupting angiogenesis via BMP/Smad/Id-1 signaling. Int J Oncol. 2016; 48: 2079-86. https://doi.org/10.3892/ ijo.2016.3443

[28] LLAMBI F, GREEN DR. Apoptosis and oncogenesis: give and take in the BCL-2 family. Curr Opin Genet Dev 2011; 21: 12-20. https://doi.org/10.1016/j.gde.2010.12.001

[29] GUPTA S, KASS GE, SZEGEZDI E, JOSEPH B. The mitochondrial death pathway: a promising therapeutic target in diseases. J Cell Mol Med 2009; 13: 1004-1033. https://doi. org/10.1111/j.1582-4934.2009.00697.x

[30] SCATENA R. Mitochondria and cancer: a growing role in apoptosis, cancer cell metabolism and dedifferentiation. Adv Exp Med Biol 2012; 942: 287-308. https://doi. org/10.1007/978-94-007-2869-1_13

[31] SPIERINGS D, MCSTAY G, SALEH M, BENDER C, CHIPUK J et al. Connected to death: the (unexpurgated) mitochondrial pathway of apoptosis. Science 2005; 310: 66-67. https://doi.org/10.1126/science.1117105

[32] KILBRIDE SM, PREHN JH. Central roles of apoptotic proteins in mitochondrial function. Oncogene 2013; 32: 27032711. https://doi.org/10.1038/onc.2012.348
[33] LALIER L, CARTRON PF, JUIN P, NEDELKINA S, MANON S et al. Bax activation and mitochondrial insertion during apoptosis. Apoptosis 2007; 12: 887-896. https://doi. org/10.1007/s10495-007-0749-1

[34] PORTER AG, JANICKE RU. Emerging roles of caspase-3 in apoptosis. Cell Death Differ 1999; 6: 99-104. https://doi. org/10.1038/sj.cdd.4400476

[35] QIAN W, XIONG X, FANG Z, LU H, WANG Z. Protective effect of tetramethylpyrazine on myocardial ischemia-reperfusion injury. Evid Based Complement Alternat Med 2014; 2014: 107501. https://doi.org/10.1155/2014/107501

[36] WAN JY, YE DY, WU P, ZHANG L, GONG X et al. [Effect of tetramethylpyrazine on lipopolysaccharides induced macrophage cyclo-oxidase-2 expression and apoptosis of cardiac myocytes]. Zhongguo Zhong Xi Yi Jie He Za Zhi 2004; 24: 906-911.

[37] CHENG XR, ZHANG L, HU JJ, SUN L, DU GH. Neuroprotective effects of tetramethylpyrazine on hydrogen peroxideinduced apoptos is in PC12 cells. Cell Biol Int 2007; 31(5): 438-443. https://doi.org/10.1016/j.cellbi.2006.10.001 